\title{
Contemplating synergistic algorithms for the NASA ACE mission
}

\author{
Gerald G. Mace*a, David O'C Starr ${ }^{\mathrm{b}}$, Roger Marchand ${ }^{\mathrm{c}}$, Steven A. Ackerman ${ }^{\mathrm{d}}$, Steven E. Platnick ${ }^{\mathrm{e}}$, \\ Ann Fridlind ${ }^{\mathrm{f}}$, Steven Cooper ${ }^{\mathrm{a}}$, Deborah G. Vane ${ }^{\mathrm{g}}$, Graeme L. Stephens \\ ${ }^{a}$ Department of Atmospheric Sciences, University of Utah, 135 South 1460 East Rm 822 (822 \\ WBB), Salt Lake City, UT, USA 84112-0110 \\ bNASA Goddard Space Flight Center, Code 612, Greenbelt, MD, USA 20771 \\ 'Department of Atmospheric Science, University of Washington, 408 ATG Building, Seattle WA, \\ USA 98195-1640 \\ ${ }^{\mathrm{d}}$ CIMSS, University of Wisconsin-Madison, 1225 West Dayton St., Madison, WI, USA 53706 \\ 'NASA Goddard Space Flight Center, Code 610, Greenbelt, MD, USA, 20771 \\ fNASA Goddard Institute for Space Studies, 2880 Broadway, Room 252, New York, NY, USA \\ 10025 \\ ${ }^{\mathrm{g}}$ Jet Propulsion Laboratory, California Institute of Technology, 4800 Oak Grove Drive, Pasandena, \\ CA, USA 91009
}

\begin{abstract}
ACE is a proposed Tier 2 NASA Decadal Survey mission that will focus on clouds, aerosols, and precipitation as well as ocean ecosystems. The primary objective of the clouds component of this mission is to advance our ability to predict changes to the Earth's hydrological cycle and energy balance in response to climate forcings by generating observational constraints on future science questions, especially those associated with the effects of aerosol on clouds and precipitation. ACE will continue and extend the measurement heritage that began with the A-Train and that will continue through Earthcare. ACE planning efforts have identified several data streams that can contribute significantly to characterizing the properties of clouds and precipitation and the physical processes that force these properties. These include dual frequency Doppler radar, high spectral resolution lidar, polarimetric visible imagers, passive microwave and submillimeter wave radiometry. While all these data streams are technologically feasible, their total cost is substantial and likely prohibitive. It is, therefore, necessary to critically evaluate their contributions to the ACE science goals. We have begun developing algorithms to explore this trade space. Specifically, we will describe our early exploratory algorithms that take as input the set of potential ACE-like data streams and evaluate critically to what extent each data stream influences the error in a specific cloud quantity retrieval.
\end{abstract}

Keywords: Clouds, Climate, Remote Sensing

\section{INTRODUCTION}

The cycling of water through the Earth's atmosphere defines the habitable climate of the planet via latitudinal energy transports and through the production of fresh water in precipitation processes. Because hydrologic processes interact over a vast continuum of spatial and temporal scales, our understanding of these processes and our ability to predict changes in the hydrologic cycle remains at a rudimentary level. Regional climate changes are in large part controlled by shifts in the general circulation of the atmosphere in response to climate forcings. The expected changes in the atmospheric general circulation drive changes in the hydrologic cycle and in the distribution of radiant heating within the climate system that feed back on the general circulation. These are the feedbacks that fundamentally determine the response of the climate system to climate forcings, and are currently the largest source of uncertainties in climate prediction.

However, the climate forcings are also poorly known. According to the IPCC ${ }^{1}$, the radiative forcing during the industrial era is uncertain by a factor of four, which renders the historic record of climate change during this period almost useless as a constraint on the climate sensitivity ${ }^{2}$. The dominant source of uncertainty in the radiative forcing is attributed to

Remote Sensing of Clouds and the Atmosphere XVIII; and Optics in Atmospheric Propagation and Adaptive Systems XVI, edited by Adolfo Comeron, et. al., Proc. of SPIE Vol. 8890, 88900I

(c) 2013 SPIE · CCC code: 0277-786X/13/\$18 · doi: 10.1117/12.2030206 
anthropogenic aerosols, partly through scattering and absorption of sunlight but mostly through the aerosol influence on clouds ${ }^{3}$.

While the physical processes that drive these forcing and feedback mechanisms are driven by circulation regimes that exist on some of the largest spatial and temporal scales in the climate system, the physical processes that define them occur at the microphysical scale where particle nucleation, growth, and evaporation dominate the evolution of condensate through a continuum of particle sizes. These microphysical processes cannot be resolved explicitly in any global climate model at present nor anytime in the near future. The representation of these important processes in models relies on the use of parameterizations that represent the statistics of the processes on the resolved scales of GCMs. Developing and evaluating parameterization for the microphysics of aerosol, clouds and precipitation requires more advanced global-scale observations than currently exist.

It is within this context that the Aerosol-Clouds-Ecosystem (ACE) - Cloud-Aerosol-Precipitation (CAP) objective is defined. Our fundamental goal is to:

Advance our ability to observe and predict changes to the Earth's hydrological cycle and energy balance in response to climate forcings, especially those changes associated with the effects of aerosol on clouds and precipitation.

We envision that ACE will continue and extend the measurement heritage that began with the A-Train and that will continue through Earthcare. In particular, ACE will continue the detailed vertical profiling of cloud and aerosol properties placed within a large spatial context into a second decade. ACE will, therefore, facilitate documentation of changes in certain key characteristics of the hydrological and aerosol cycles over this extended period of time.

Although the findings of the ACE mission predecessors will be groundbreaking, information on the microphysics of clouds, aerosol and precipitation from A-Train and Earthcare will remain limited. Our vision to address the overarching science objective, and the science questions that emerge from that objective, is motivated by a realization that an understanding of the physical processes that relate aerosols, clouds, and precipitation with atmospheric motions begins with the essential ability to infer vertical profiles of aerosol, cloud, and precipitation microphysical properties from measurements. It is this provision for new microphysical information, vital for addressing climate science goals in the coming decades, that differentiates ACE from its predecessor missions.

In the following sections, we articulate science questions, describe the geophysical parameters that must be retrieved from ACE measurements to address those science questions, and then describe in detail the measurements that will be needed to retrieve the geophysical parameters.

\section{MICROPHYSICS, SIZE DISTRIBUTION MOMENTS, AND ACE}

Our overarching scientific objective is to improve our understanding of the physical processes that cause aerosols, clouds, and precipitation to interact and evolve within the atmosphere. Because aerosol, clouds, and precipitation exist in the atmosphere as distributions of particles with varying sizes and because the evolution of the physical and optical cloud properties comes about through changes in these distributions, it is necessary that we acquire vertically resolved information about such distributions. However, vertical microphysics alone is not sufficient for answering the full suite of physical interactions and related science questions; information on cloud radiative and macrophyscial properties, cloud vertical motion, and environmental conditions in which the clouds and aerosols are embedded are also needed.

\subsection{Scope of the Problem}

Neglecting aerosol for the moment, in the most general case, a small atmospheric volume (say a $100 \mathrm{~m}$ sized cube) could contain liquid and ice phases whose particle size distributions (PSD) include cloud droplet-sized and precipitation-sized particles. Conceptually, we can define the atmospheric volume using four distribution functions, with two for water (a cloud mode and a precipitation mode) and two for ice (a small ice mode and a precipitating ice mode). It is often assumed that each of the distribution modes can be described approximately but analytically with a modified gamma or lognormal function. Since these distribution functions are characterized by at least 2 independent parameters, this generalized problem contains a minimum of 6 unknowns, and a unique solution for the distribution parameters would require that number of measurements that each provide unique information. This extreme complexity can often be 
reduced in regions where only the liquid or only the ice phase is physically possible; however, it is often difficult to empirically discount the possibility that particle size distributions are not bimodal containing both cloud and precipitation modes. Stratocumulus clouds, for instance, very often contain a drizzle mode that may or may not extend to the surface as sensible precipitation. Very often the number of unknown variables can be reduced through empirical assumptions. However, almost never can the number of unknowns be reduced to less than 2 or 3 parameters in each vertical interval. To derive a profile of microphysical properties, therefore, a minimum of 3 (and often more) observations that contain unique information about the cloudy volume is necessary to obtain a meaningful description of the physical properties of that cloudy volume.

Remote sensors provide measurable quantities that are sensitive to certain moments of the PSD. The A-Train reliably provides profiles of radar reflectivity (i.e. the $6^{\text {th }}$ moment of a cloud mode liquid PSD - proportional to the square of the total condensed mass) and lidar backscatter $\left(2^{\text {nd }}\right.$ moment of the PSD proportional to the cross sectional area) as well as constraints on the vertical integrals of various PSD moments with quantities such as optical thickness and liquid water path (vertically integrated $2^{\text {nd }}$ and $3^{\text {rd }}$ moments of the PSD, respectively) by MODIS and the AMSRE-E microwave radiometer. However, in no case is there sufficient information in any A-Train vertical profile to derive realistic size distributions without imposing additional a-priori assumptions to reduce the dimensionality of the problem. These assumptions increase retrieved parameter uncertainty significantly and result often in large retrieval biases. Earthcare will add crude measurements of Doppler Velocity that will add information in the vertical column regarding precipitation. Even with Earthcare, however, the problem remains severely under-constrained in nearly all retrieval circumstances.

This discussion illustrates a degree of complexity that helps explain why the problem of determining cloud microphysics from remote sensing measurements has persisted over decades and will continue to remain an essentially unsolved problem even as the technology in space improves in the years preceding ACE.

The forgoing discussion is also not just a remote sensing problem. Recently developed parameterizations for mesoscale and climate models ${ }^{4}$ make a similar set of assumptions regarding multiple modes of large and small particles and then attempt to characterize, using simplified physics, how the distribution moments (i.e. the water content and total particle number) evolve due to the interaction between physical processes and the thermodynamic and dynamic state of the atmosphere. In other words, the philosophical approach to this parameterization, which is now the operational cloud scheme in the community atmosphere model ${ }^{5}$, is identical to the philosophy we have adopted for ACE. Understanding the physical processes that control the hydrological cycle and its radiative influence requires the sufficient characterization of aerosol, cloud and precipitation particle size distributions through multiple synergistic active and passive measurements.

\subsection{The ACE Science Traceability Matrix for Clouds, Aerosols, and Precipitation}

Our conceptual approach to conceiving the ACE mission is to merge what is possible technologically with what is necessary scientifically to solve the problem of understanding aerosol, cloud, and precipitation processes and representing those processes in models. We begin this process by articulating a set of science questions (discussed more fully in Section 3) that emerges from our overarching goal and then envision a set of geophysical parameters and requirements on those geophysical parameters to address the questions. From the requirements on geophysical parameters, we consider which of a set of technologically feasible measurements would supply the necessary information to retrieve the parameters to within the required accuracy under the challenging conditions often present in the atmosphere (discussed in Section 4). This approach results in a matrix that allows the tracing of science requirements to measurement requirements via the geophysical parameters (Table 2.1) - i.e. a Science Traceability Matrix (STM). We introduce and briefly discuss the STM here and then devote the balance of this document to a more detailed justification of the various elements of the STM.

The science questions discussed in Section 3 can be broadly categorized in terms of morphology, microphysics, aerosol processes, and energetics. These categories of questions relate to sets of geophysical parameters necessary to addressing the science questions. These questions and associated geophysical parameters are structured in the STM in a very specific hierarchy. For instance, addressing the morphological questions that refer to the occurrence and macroscale structure of hydrometeors and aerosols, the associated geophysical parameters listed under that category in the embedded 
table in column 2 would be required (i.e. parameters 1-9). To address the questions regarding the microphysical processes and/or aerosols, the additional geophysical parameters 10-14 would also be required in addition to the morphological parameters. To address questions of energetics, parameters 15-19 are necessary as well as parameters 114.

We have considered the technologically feasible instruments and assembled a synergistic set in the right-most column of Table 2.1. Instruments listed in Bold font are those that we consider to be required to meet the basic science goals of ACE CAP while the instruments listed in italicized font are those that add information and are highly desired for for ACE. Similarly, the geophysical parameters that contribute to the broad topical categories are also listed. Those parameters listed in bold font are those that can be directly observed by an instrument while those listed in italicized font are those that must be diagnosed from some sort of algorithm. The instruments that can either observe directly or that contribute to synergistic algorithms to diagnose a specific geophysical quantity appear next to that geophysical parameter in brackets. Additional information regarding what each instrument contributes to the measurement synergy is given in Table 4.2. The actual requirements for each of the instruments are still under study. 
Table 2.1. Simplified ACE Science Traceability Matrix.

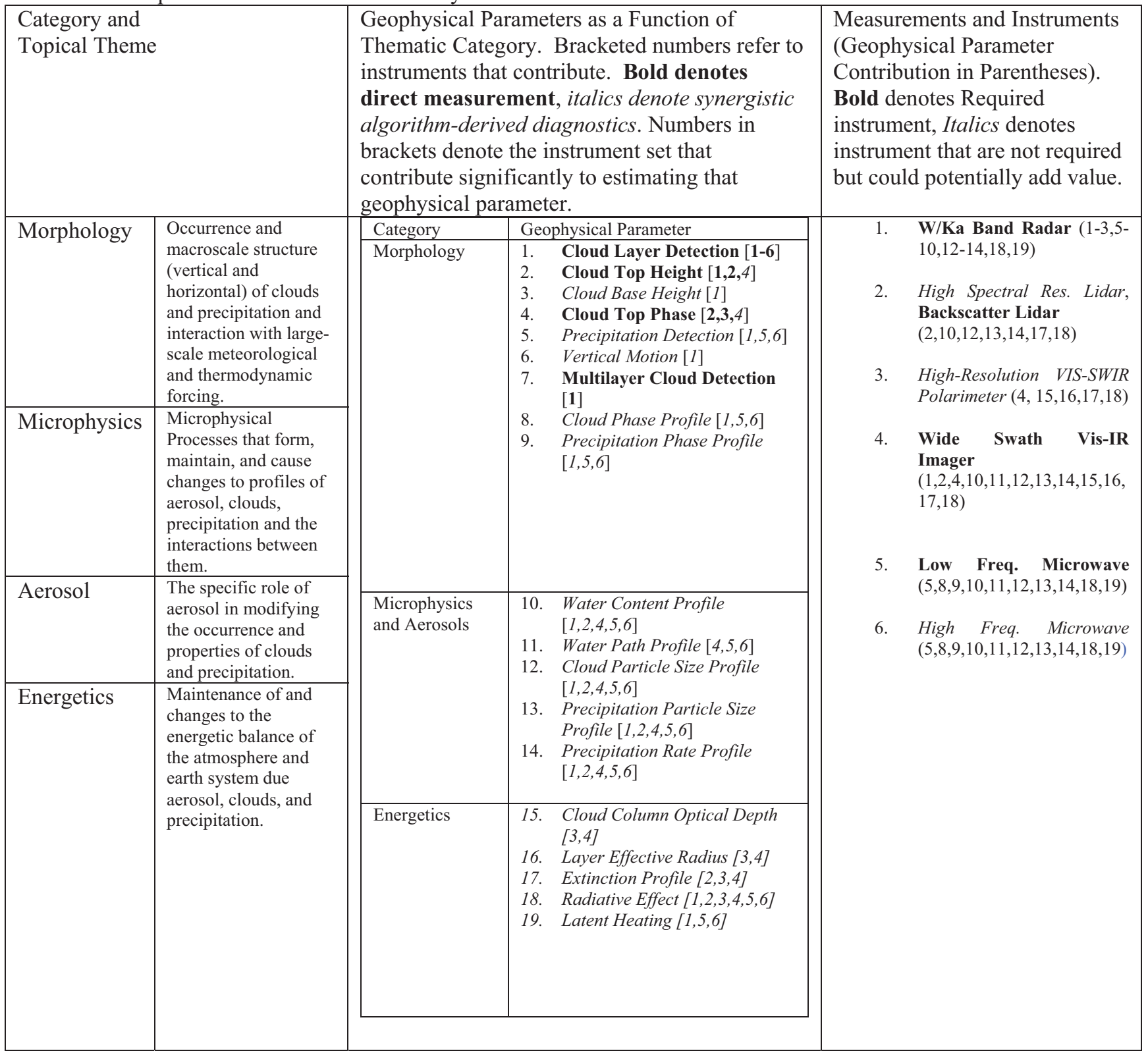

\subsection{Estimating Accuracy Requirements for Geophysical Parameters}

The requirements for the geophysical parameters listed in Table 2.1 need to be traceable to physically meaningful and scientifically defensible standards. Since heating by clouds and precipitation is a fundamental component of the hydrological cycle feedbacks in the atmosphere ${ }^{6}$, we attempt to link our geophysical requirements to cloud-induced heating rates - hereafter termed cloud forcing. This forcing can include radiative as well as latent heating. For most clouds, the predominant heating would be the radiative component, however, the heating from deep cumulus and frontal clouds can be predominantly derived from latent heating.

We define $1 \mathrm{~K} \mathrm{day}^{-1} \mathrm{~km}^{-1}$ as a reference cloud forcing to which we link our geophysical parameter requirements. This magnitude of cloud forcing is approximately $1 / 3$ to $1 / 2$ that of the clear sky-cooling rate in the tropical troposphere below 
$10 \mathrm{~km}$ so that a cloud-induced heating of this magnitude would offset the clear sky cooling by $30-50 \%$. We consider this reference forcing to be a target accuracy that would be found by aggregating heating rates over a period of 24 hours at a particular location or over an equivalent synoptic spatial scale. With this accuracy requirement, and recognizing that the heating rate is a vertical convergence of radiant flux, we can ask to what accuracy must the net flux be determined over our working vertical scale to achieve an accuracy of $1 \mathrm{~K} \mathrm{day}^{-1} \mathrm{~km}^{-1}$. Ignoring 3-d radiative effects, we assume that cloud heating can only occur in cloudy columns so some estimate of the cloud fractional coverage is needed over the assumed spatial scale. Also, depending on the cloud properties, the heating is very often not distributed evenly through the cloud layer but is confined to the first several optical depths from the cloud boundary.

Using cirrus clouds as an example, we assume coverage on the order of $20 \%$. The heating is typically confined to the lowest few hundred meters from the layer boundary. Then, 25-30 K/day would be the target cloud forcing accuracy of an individual measurement. We can estimate the precision necessary in up or downwelling flux to obtain such a heating rate accuracy using standard error propagation techniques ${ }^{7}$. Since the cloud radiative forcing is the convergence of net radiant flux into a volume, we approximate the vertical derivative with a simple centered difference formula:

$H_{y}=-\frac{1}{\rho c_{p}} \frac{\partial F_{n e t, y}}{\partial z} \cong-\frac{1}{\rho c_{p}} \frac{F_{n e t, y_{+1}}-F_{n e t, y_{-1}}}{z_{+1}-z_{-1}}$ where $\rho$ is the air density, $c_{p}$ is the specific heat at constant pressure, and $z$ is the height and the subscripts +1 and -1 indicate the vertical levels above and below a level of interest. We are also primarily interested in the effects of clouds and, therefore, difference $H_{y}$ in cloudy skies with a calculation that has cloud removed with no other changes to the temperature or moisture profiles. Considering only the first and second order terms that would contribute to the uncertainty in $H$, we can write,

$\sigma_{H_{y}}^{2} \cong \frac{1}{\Delta z^{2} \rho c_{p}}\left[\left(\sigma_{F_{2, y} \uparrow}^{2}+\sigma_{F_{2, y} \downarrow}^{2}+\sigma_{F_{1, y} \uparrow}^{2}+\sigma_{F_{1, y} \downarrow}^{2}\right)+2\left(\begin{array}{l}\sigma_{F_{1, y} \uparrow F_{1, y} \downarrow}^{2}+\sigma_{F_{1, y} \uparrow F_{2, y} \uparrow}^{2}+ \\ \sigma_{F_{1, y} \uparrow F_{2, y} \downarrow}^{2}+\sigma_{F_{1, y} \downarrow F_{3, y} \uparrow}^{2}+\sigma_{F_{1, y} \downarrow F_{2, y} \downarrow}^{2}+\sigma_{F_{2, y} \downarrow F_{2, y} \uparrow}^{2}\end{array}\right)\right]$ where

$\Delta z^{2}=\left(z_{+1}-z_{-1}\right)^{2}$ and terms such as $\sigma_{F_{1, y}}^{2} \uparrow F_{1, y} \downarrow$ represent an error covariance of the indicated fluxes and y is taken to

mean either the solar or IR flux. The terms in the first parenthetical expression inside the brackets are a function of the uncertainties at the layer. The terms in the second parenthetical expression represent error covariances between upwelling and downwelling fluxes and are assumed to be approximately represented by the error covariances of the upand downwelling fluxes at the TOA and surface. With these approximations, we write

$\sigma_{H}^{2} \cong \frac{8}{\Delta z^{2}\left(\rho c_{p}\right)^{2}}\left[\sigma_{F}^{2}+r_{F \downarrow \uparrow} \sigma_{F}^{2}\right]$

In the analysis of the error covariance, $r_{F \uparrow \downarrow} \square-0.25$, we find using ground-based data a negative correlation between the downwelling surface radiation flux errors and the upwelling TOA flux errors ${ }^{7}$. This negative correlation makes intuitive sense since an error resulting in too much (little) solar flux at the surface would imply a cloud albedo that is too low (high) leading to too little (much) flux at the TOA compared to reality. The negative error covariance has the interesting implication of mitigating the heating error that would arise if the covariance were not included in equation 2.

If we further simplify equation 2 and assume that the up and downwelling errors would be the same, then we can solve for the allowable error in the flux:

$\sigma_{F} \approx \sqrt{\frac{\sigma_{H}^{2} \Delta z^{2}\left(\rho c_{p}\right)^{2}}{8\left(1+r_{F \uparrow \downarrow}\right)}}$

So, assuming something like a $30 \mathrm{~K}_{\text {day }}^{-1}$ target heating rate accuracy, a $100 \mathrm{~m}$ vertical scale over which the heating would occur at an atmospheric density of $0.3 \mathrm{~kg} / \mathrm{m} 3$, we arrive at $\sigma_{F} \approx \sqrt{\frac{\sigma_{H}^{2} \Delta z^{2}\left(\rho c_{p}\right)^{2}}{8\left(1+r_{F F}\right)}} \approx 7 W \mathrm{~m}^{-2}$.

The flux precision ( $7 \mathrm{~W} \mathrm{~m}^{-2}$ for cirrus) is a very important but highly uncertain quantity that depends on the assumptions we have made. It connects our target accuracy of $1 \mathrm{~K}^{\text {day }}{ }^{-1} \mathrm{Km}^{-1}$ to the precision of a radiant flux derived from 
geophysical parameters that are in turn derived from measurements. We estimate that the uncertainty in $\sigma_{F}$ is on the order of $100 \%$ given the assumptions made in its derivation. For instance, if we assume that the vertical scale over which the heating must be resolved is $200 \mathrm{~m}$, then $\sigma_{F} \approx 3.5 \mathrm{~W} \mathrm{~m}^{-2}$. While we have used cirrus as an example, the approach can be generalized by defining a typical fractional cloud coverage, and estimating over what fraction of a $1 \mathrm{~km}$ scale, the heating would be confined given a typical optical density of the cloud type of interest. The question to be addressed now is how this requirement projects onto accuracy requirements for geophysical parameters. This could be accomplished in several ways. We adopt a simple approach of considering cloud properties (water content, particle size, and number densities) that are typical of the cloud type of interest. From these typical properties, we can ask to what accuracy must the properties be inferred to achieve the previously identified flux precision that is derived from the $1 \mathrm{~K} \mathrm{day}^{-1} \mathrm{~km}^{-1}$ accuracy requirement.

Continuing with cirrus clouds as an example, ground-based remote sensing data suggest that cirrus layers with IWP of approximately $20 \mathrm{~g} \mathrm{~m}^{-2}$ have the most significant influence on the radiation budget. This is determined by convolving the frequency of occurrence of IWP with the radiative impact of cirrus as a function of IWP. According to typical radiative parameterizations ${ }^{8}$, assuming a 30 micron effective radius and a typical layer thickness of $1.5 \mathrm{~km}$ such layers have infrared optical depths on the order of 1. Using the sensitivity study of Vogelmann and Ackerman ${ }^{9}$ and assuming a typical value for upwelling IR flux of $240 \mathrm{~W} / \mathrm{m}^{2}$, a requirement of $7 \mathrm{~W} / \mathrm{m}^{2}$ scales to an infrared optical depth precision requirement of approximately $10 \%$. Holding the particle size constant, a precision requirement in IWP of approximately $2 \mathrm{~g} \mathrm{~m}^{-2}$ or $0.001 \mathrm{~g} \mathrm{~m}^{-3}$ in IWC is determined (assuming a typical layer thickness of $2 \mathrm{~km}$ ). These precision targets are approximately $10 \%$ of the assumed values using $20 \mathrm{~g} \mathrm{~m}^{-2}$ as typical. Similarly, holding IWP constant and allowing particle size to vary, we find that the particle size must be determined to within 3.5 microns to maintain the optical depth within $8.5 \%$ of the actual value - again this is roughly $10 \%$ of a typical particle size magnitude.

For the macroscopic quantities, assuming that any error in cloud cover will be due to measurements sensitivity, we can ask what minimum sensitivity would allow us to sense layers that perturb the upwelling IR flux by an amount (i.e. $6.5 \mathrm{~W}$ $\mathrm{m}^{-2}$ ) that corresponds to the target accuracy of $1 \mathrm{~K} \mathrm{day}^{-1} \mathrm{~km}^{-1}$. For cirrus we can quantify this requirement in terms of optical depth. Simple arguments (Stefan-Boltzmann law at a typical cirrus temperature) suggest that all cirrus above an IR optical depth of 0.05 or a visible optical depth of 0.1 would need to be sensed. Given our present understanding of the distribution of cirrus properties in the atmosphere, this would include approximately $90 \%$ by occurrence of all cirrus $^{10}$. The present A-Train sensitivity exceeds this precision requirement when considering the capabilities of the CALIPSO lidar although not with the Cloudsat radar taken alone. Our goal would be to observe $90 \%$ of all cirrus with a millimeter radar on ACE. The vertical resolution requirement can also be linked to a $6.5 \mathrm{~W} / \mathrm{m}^{2}$ change in upwelling IR flux assuming a moist adiabatic lapse rate or about $400 \mathrm{~m}$. Since cirrus are often horizontally extensive, we can link the horizontal resolution requirement to aircraft data analyses ${ }^{11}$ that suggest that much of the variability in these clouds occur on spatial scales exceeding several hundred meters.

The logic described in the previous paragraphs is used to define the geophysical requirements for cirrus clouds. With some modification, this logic can be extended to boundary layer clouds where we combine marine stratus, trade cumulus, and Arctic stratus in this discussion. These clouds are found to have a marked influence on the heat balance of the ocean mixed layer - especially in the subtropics due to their albedo ${ }^{12}$. Since the primary effect of these clouds on the climate system is due to reflection of incoming solar, we can set the precision target for derived radiative fluxes to be roughly $10 \%$ of the diurnally average solar flux at the surface or approximately $25 \mathrm{~W} \mathrm{~m}^{-2}$. From an infrared perspective, these clouds tend to also cool the lower troposphere. Using logic as for cirrus, we can estimate the IR heating rate error assuming that the majority of the heating occurs in the upper 10's of meters of the optically thick layers and that regional cloud coverage is on the order of $60-70 \%$. To meet our accuracy requirement of $1 \mathrm{~K} \mathrm{day}^{-1} \mathrm{Km}^{-1}$, our instantaneous heating rate precision values would be on the order of $80 \mathrm{~K} \mathrm{day}^{-1}$ at cloud base and top. This, in turn is equivalent to an up and downwelling flux precision of $30 \mathrm{~W} \mathrm{~m}^{-2}$ - similar to the $10 \%$ surface solar flux requirement.

With the radiative flux precision estimated, it is straightforward to map this requirement to geophysical parameters. The analysis of Marchand et al. ${ }^{13}$ is particularly useful since they examine the sensitivity of downwelling solar fluxes on LWP uncertainties. Typical water paths are found to be on the order of $100 \mathrm{~g} \mathrm{~m}^{-2}$ and particle sizes on the order of 10 microns ${ }^{13,14}$. A $25-30 \mathrm{~W} \mathrm{~m}^{-2}$ flux precision for a $100 \mathrm{~g} \mathrm{~m}^{-2}$ boundary layer cloud with effective particle size of 10 microns maps to a precision requirement in LWP of approximately $15 \mathrm{~g} \mathrm{~m}^{-2}(15 \%)$, a layer-mean effective radius 
precision of approximately 1.5 microns (15\%), and an optical depth precision of approximately 4 (20\%). Assuming a vertical scale of $500 \mathrm{~m}$, we can establish the LWC precision to approximately $25 \%$ of the typical value of $0.2 \mathrm{~g} \mathrm{~m}^{-3}$ or $0.05 \mathrm{~g} \mathrm{~m}^{-3}$ (here we have assumed there will be on average 5 LWC measurements in each layer with the errors in LWC random and uncorrelated from each other). Similarly for the vertically resolved effective radius, a precision of 2.5 microns is required. To achieve the optical depth precision requirements, the extinction precision would need to be on the order of $10 \mathrm{~km}^{-1}$.

Since these clouds tend to be geometrically thin (several hundred meters to a few km) yet vary considerably in properties over this depth, it will be particularly important that their vertical structure is resolved adequately. This will likely require vertical resolutions on the order of $100 \mathrm{~m}$ or better to adequately resolve the variability of microphysical properties over the depth of the layer.

Estimated aerosol effects on broken boundary layer clouds are used as the basis for deriving parameter requirements for aerosol number size distribution properties. Large-eddy simulation (LES) of broken trade cumulus with size-resolved cloud and aerosol size distributions using the DHARMA model were evaluated to estimate that ambient aerosol number concentrations in the lowermost $500 \mathrm{~m}$ of clear columns likely demonstrate similar percentage changes as dry aerosol properties over the $0.1-1$ micron size range ${ }^{15}$. The mean daytime shortwave forcing induced by a cloud albedo change resulting from a 100\% increase in droplet number concentration (all other aerosol properties identical, using droplets as a proxy for aerosol number) can be estimated in cloudy columns, assuming plane-parallel homogeneous cloud layer with initial albedo of 0.5 over a non-reflecting surface, as $\Delta \mathrm{CRF}=-0.5 \mathrm{~S} \mathrm{~T} 2 \Delta \mathrm{A}$, where $0.5 \mathrm{~S}$ is mean insolation at a solar zenith angle of $60^{\circ}\left(685 \mathrm{~W} \mathrm{~m}^{-2}\right)$, $\mathrm{T}$ is atmospheric transmissivity (0.9), albedo change $\Delta \mathrm{A}(0.058)$ is evaluated from $\mathrm{A}(1$ A) $/ 3 * \ln (\Delta \mathrm{N} / \mathrm{N})^{16}$, and therefore $\Delta \mathrm{CRF}=-32 \mathrm{~W} \mathrm{~m}^{-2}$. This can be related to surface flux precision under boundary layer cloudy columns if divided by transmissivity, giving $-35 \mathrm{~W} \mathrm{~m}^{-2}$. The LES results discussed above also indicate that in available well-defined case studies, simultaneous changes in cloud fraction and liquid water path tend to offset approximately two-thirds of the Twomey effect in cloud columns, giving a range of -11 to $-35 \mathrm{~W} \mathrm{~m}^{-2}$ as the range encompassed by a small set of available case studies and a reasonable back-of-the-envelope calculation. This range encompasses the $25-30 \mathrm{~W} \mathrm{~m}^{-2}$ precision target identified above for cloud properties, suggesting that the parameter requirement for aerosol number concentration in the $0.1-1$ micron size range corresponds to cloudy-column radiative impacts that are roughly the same magnitude as the precision at which cloud properties are to be measured. Simulated case studies also suggest that the parameter requirement for aerosol effective variance (50\%) produces similar magnitude effects on cloud properties in most cases considered. The parameter requirement for aerosol effective radius $(10 \%)$ corresponds to less than a 50\% change in effective variance for the aerosol cases considered and is therefore expected to produce radiative impacts no larger than the other target parameter requirements in the $0.1-1$ micron size range.

Using the above methodology, we can establish a current best estimate of the requirements for geophysical parameters along the ACE nadir track. Our current best estimates of these requirements are listed in Table 2.2. An addition that we add to Table 2.2 is consideration of swath requirements. Much of the discussion thus far has focused on the requirements along a nadir track. It is unclear as of this writing what the technological possibilities for swath measurements of the active remote sensors can be in the ACE timeframe. However, we are relatively more certain of the available possibilities along a nadir track. Therefore, much of the process level requirements are specifically targeted at the nadir swath. Several of the passive instruments will be designed to return information along a wide swath in a manner similar to heritage instruments that have flown on numerous other satellites. The swath information will provide valuable context for the more detailed nadir swath measurements are considered a requirement for ACE. The requirements for this information are, therefore, listed in Table 2.2. 
Table 2.2. Estimated accuracy requirements of the geophysical parameters listed in the ACE Science Tracability Matrix in table 2.1. The font convention of Table 2.1 is adopted in the second column. We also use the convention (R) to denote an accuracy requirement and $(\mathrm{G})$ to denote a goal. N/A denotes that this quantity will not be retrieved for the wide swath and TBD refers to a requirement that is still under study.

\begin{tabular}{|c|c|c|c|}
\hline Category & Geophysical Parameter & $\begin{array}{l}\text { Accuracy Requirement: } \\
\text { Nadir Track }\end{array}$ & $\begin{array}{l}\text { Accuracy } \\
\text { Requirement: Wide } \\
\text { Swath }\end{array}$ \\
\hline \multirow[t]{9}{*}{ Morphology } & 1. Cloud Layer Detection & $\begin{array}{l}2 \% \text { miss maximum miss } \\
\text { rate }\end{array}$ & $\begin{array}{l}\% \text { (optical } \\
\text { depth }>0.3)\end{array}$ \\
\hline & 2. Cloud Top Height & $250 \mathrm{~m}(\mathrm{R}), 100 \mathrm{~m}(\mathrm{G})$ & $\begin{array}{l}150 \mathrm{~m} \text { (ice), } 1 \mathrm{~km} \\
\text { (liquid) }\end{array}$ \\
\hline & 3. Cloud Base Height & $250 \mathrm{~m}(\mathrm{R}), 100 \mathrm{~m}(\mathrm{G})$ & N/A \\
\hline & 4. Cloud Top Phase & $5 \%$ maximum error & $20 \%$ maximum error \\
\hline & 5. Precipitation Detection & $10 \%$ maximum miss rate & $20 \%$ maximum error \\
\hline & 6. Vertical Motion & TBD & N/A \\
\hline & $\begin{array}{l}\text { 7. Multilayer Cloud } \\
\text { Detection }\end{array}$ & $5 \%$ maximum miss rate & $\begin{array}{l}\text { Detection of cirrus } \\
\text { (optical depth } \sim 0.3-7 \\
\text { depending on } \\
\text { geometry) over lower } \\
\text { water cloud }\end{array}$ \\
\hline & 8. Cloud Phase Profile & $20 \%$ maximum miss rate & N/A \\
\hline & $\begin{array}{l}\text { 9. Precipitation Phase } \\
\text { Profile }\end{array}$ & $10 \%$ maximum miss rate & N/A \\
\hline \multirow[t]{5}{*}{ Microphysics and Aerosols } & 10. Water Content Profile & $\begin{array}{l}10-25 \% \text { depending on } \\
\text { cloud type }\end{array}$ & N/A \\
\hline & 11. Water Path & $10 \%$ & $25 \%$ \\
\hline & $\begin{array}{l}\text { 12. Cloud Particle Size } \\
\text { Profile }\end{array}$ & $\begin{array}{l}10-25 \% \text { depending on } \\
\text { cloud typ }\end{array}$ & N/A \\
\hline & $\begin{array}{l}\text { 13. Precipitation Particle } \\
\text { Size Profile }\end{array}$ & $10 \%$ & $\mathrm{~N} / \mathrm{A}$ \\
\hline & $\begin{array}{l}\text { 14. Precipitation Rate } \\
\text { Profile }\end{array}$ & $\begin{array}{l}20-50 \% \text { depending on type } \\
\text { and intensity }\end{array}$ & N/A \\
\hline \multirow[t]{5}{*}{ Energetics } & 15. Column Optical Depth & $10 \%$ & $20 \%$ \\
\hline & 16. Layer Effective Radius & $10 \%$ & $20 \%$ Liquid, $30 \%$ (ice) \\
\hline & 17. Extinction Profile & $5 \%$ & N/A \\
\hline & 18. Radiative Effect & $\begin{array}{l}\text { The lesser of } 10 \% \text { or } 25 \mathrm{~W} \\
\mathrm{~m}^{-2}\end{array}$ & $10 \mathrm{~W} \mathrm{~m}^{-2}$ \\
\hline & 19. Latent Heating & $5 \mathrm{~K}$ day $^{-1} \mathrm{~km}^{-1}$ & N/A \\
\hline
\end{tabular}

\section{ACE MEASUREMENT STRATEGY}

Understanding climate and predicting changes in the hydrologic cycle in the next decade will require in depth understanding of the processes that generate clouds and precipitation. A large set of observations of cloud, aerosol and precipitation properties over a wide range of atmospheric conditions are necessary to unravel the relationships of these complex processes. Much of the interaction between cloud, aerosol and precipitation, while embedded within a synoptic-scale context, occurs at the microphysical level, where cloud particle nucleation, growth, coalescence, and evaporation takes place. Therefore, in addition to traditional retrievals of macrophysical and radiative properties (cloudtop-height, cloud and aerosol single-scattering albedo, optical thickness), it is critical to obtain information on the microphysics of clouds, aerosols and precipitation through the depth of the atmosphere in which they exist. In particular, many of the science questions that led to the geophysical parameters listed in Table 2.1 require vertically-resolved observations of the distribution of cloud ice and liquid water content, characterization of cloud and precipitation particle 
sizes, discrimination of cloud phase and aerosol and hydrometeor number concentration, and characterization of aerosol type (including information on aerosol optical and compositional properties) along with the meteorological conditions of the observed scene in particular cloud-scale vertical motion

Our measurement strategy for ACE is to assume a "two swath" approach, where vertically pointing radar and lidar, as well as high resolution imager data provide observations on a "narrow swath" whose width is to be determined but will be on the order of several 10's of km, while lower resolution observations from a variety of passive systems, including microwave and sub-millimeter wavelengths, while crucial for detailed retrievals along the nadir swath also provide additional context over a much larger domain (again width is TBD but is expected to be on the order $1500 \mathrm{~km}$ ).

With regard to the narrow swath, the power of combining spectral radiance data from passive sensors with active instruments (lidar and radar) continues to be demonstrated by many researchers using A-Train data. Fascinating new results on cloud and rain microphysics and the interaction of aerosol and clouds are just beginning to emerge from this combination of measurements. Improvements in instrument capabilities (Table 3.1) for ACE will significantly enhance retrieval capability and the accuracy with which these quantities can be inferred.

With regard to wide swath observations, the representation of processes affecting cloud properties cannot necessarily be captured by instantaneous measurements in a narrow vertical swath since the temporal/spatial history of the relevant influences can come from well beyond the active remote sensing curtain. It is critical that ACE be capable of passive observations across a range of horizontal scales so as to capture the larger cloud, aerosol, and meteorological context (i.e. synoptic circulation patterns) for which the specialized curtain retrievals are obtained. Further, large-scale cloud observations allow for the feasibility of supporting process-oriented case studies and events of interest (e.g., aerosol production and advection events, interactions with isolated/inhomogeneous cloud fields, etc.) that have historically been important in model development. While we anticipate new understandings through joint analysis of large-scale observations and analyzed dynamical fields from global models, retrievals on scales much larger than the narrow swath (of active sensors) also enable cloud assimilation which we envision as a pathway to model improvement since assimilation analysis provides meaningful insight into physical processes and model diagnostics. Finally, we desire swath coverage commensurate with aerosol observations, i.e., off-curtain aerosol retrievals ought to be accompanied by best cloud retrievals possible for process and correlative studies. There is a clear synergy between our wide and narrow swath objectives. While the wide swath information will be less detailed, the contextual information that the wide swath can provide to the narrow will ultimately be important for the reasons cited above.

Determination of the cloud, aerosol, and precipitation microphysical properties from space is challenging. These properties result from a distribution of particles which have many degrees of freedom including a wide range of sizes and large spatial variations (including especially in the vertical) and therefore cannot be accurately determined using observations from any single satellite instrument. For example, while one can estimate the vertical profile of cloud water content of a non-precipitating cloud from millimeter-wavelength radar observations of cloud reflectivity alone, this estimate is very uncertain because the radar-reflectivity is a strong function of both the sizes of the cloud particles and the amount of water. Therefore, retrieving the water content using only radar-reflectivity observations requires making assumptions about the sizes of the cloud particles. Even in the simple case of ice-only cirrus clouds, for example, the uncertainty in the radar-only ice water content can be more than $100 \%$. The uncertainty in the IWC retrieval can be reduced by a factor of 3 if the retrieval is constrained by observations of IWP from other measurements at the submillimeter wavelengths, for instance.

Therefore, our strategy is to obtain multiple observational constraints on the cloud, aerosol and precipitation microphysical properties using carefully collocated measurements from a combination of synergistic active and passive instruments. Using our current understanding of the technological possibilities that would potentially be available to ACE, Table 3.1 lists the potential instruments and associated measurements and how observations from these instruments help constrain microphysical retrievals. 
Table 3.1 Potential ACE Instrument and Measurements and their contribution to Level 1 Geophysical Parameters. The instruments that we consider required are denoted in Table 2.1

\begin{tabular}{|c|c|c|c|}
\hline Instrument & Measurement & $\begin{array}{l}\text { Cloud Microphysical } \\
\text { Constraint }\end{array}$ & $\begin{array}{l}\text { Additional } \\
\text { Information }\end{array}$ \\
\hline $\begin{array}{l}\text { High r Spectral } \\
\text { Resolution } \\
\text { (HSRL) }\end{array}$ & Extinction & $\begin{array}{l}2^{\text {nd }} \text { moment of cloud drop } \\
\text { size distribution }\end{array}$ & 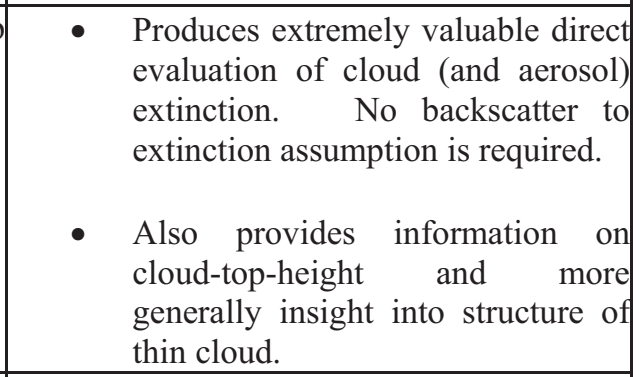 \\
\hline $\begin{array}{l}\text { Dual Frequency } \\
\text { 94/35 GHz } \\
\text { Radar }\end{array}$ & Radar Reflectivity & $\begin{array}{lll}6^{\text {th }} \text { moment of cloud drop } \\
\text { size disribution for } \\
\text { particles less than } \sim 0.3 \\
\text { mm }\end{array}$ & $\begin{array}{l}\text { Difference in response of } 95 / 35 \\
\text { GHz radar reflectivity and Doppler } \\
\text { velocity for larger particles }(>\sim 0.3 \\
\text { mm) can be used to identify the } \\
\text { presence of such particles and help } \\
\text { characterize the microphysics of } \\
\text { this part of the distribution. } \\
\text { - } \\
\text { Differential attenuation with } \\
\text { respect to } 94 \mathrm{GHz} \text { is likely to prove } \\
\text { useful in identification of cloud and } \\
\text { precipitation type (phase) and } \\
\text { retrieval of precipitation water } \\
\text { content. }\end{array}$ \\
\hline & Doppler Velocity & $\begin{array}{l}2^{\text {nd }} / 3^{\text {rd }} \text { moment of drop size } \\
\text { distribution (weighted by } \\
94 \mathrm{GHz} \text { reflectivity). }\end{array}$ & $\begin{array}{l}\text { Doppler velocity is a measure of } \\
\text { total velocity of the cloud particles. } \\
\text { In convective cores, the velocity is } \\
\text { dominated by cloud vertical } \\
\text { motion. In most other conditions, } \\
\text { the velocity can be separated into } \\
\text { contributions from particle fall } \\
\text { velocity and cloud motion. } \\
\text { - Cloud liquid water drops generally } \\
\text { fall too slowly to be measured via } \\
\text { this technique but is very useful for } \\
\text { identification, and characterization } \\
\text { of ice clouds, snow, drizzle, and } \\
\text { rain. }\end{array}$ \\
\hline & $\begin{array}{l}\text { Path Integratec } \\
\text { Attenuation }\end{array}$ & $\begin{array}{l}\text { Total column liquid water } \\
\text { path. }\end{array}$ & $\begin{array}{l}\text { - One can use surface reflectance to } \\
\text { estimate total attenuation in the } \\
\text { radar in the column, when the radar } \\
\text { is not totally attenuated. The } \\
\text { attenuation is determined largely } \\
\text { by the amount of liquid water } \\
\text { (cloud and precipitation) in the } \\
\text { column. }\end{array}$ \\
\hline
\end{tabular}




\begin{tabular}{|c|c|c|c|}
\hline \begin{tabular}{|l|} 
High Resolution \\
Multi-angle \\
Imaging \\
Polarimeter \\
(UV, Visible, and \\
Shotwave \\
Infrared) \\
\end{tabular} & $\begin{array}{l}\text { UV, Visible and } \\
\text { shortwave infrared } \\
\text { radiances } \\
\text { multiple } \\
\text { angles. } \\
\text { Polarized } \\
\text { reflectances } \\
\text { somer visible } \\
\text { wavelengths. }\end{array}$ & 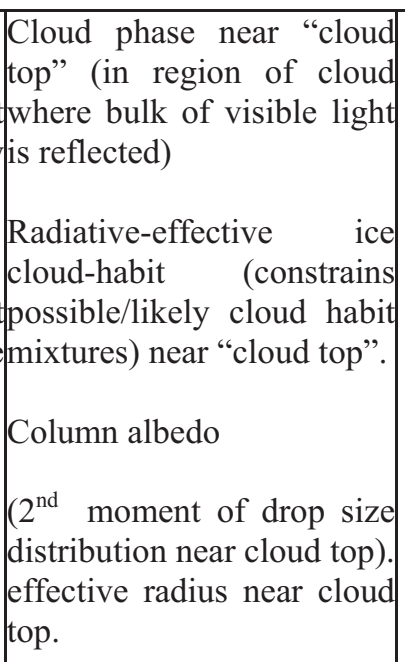 & $\begin{array}{l}\text { - Multi-view-angle imagery can also } \\
\text { be used with stereo-imaging } \\
\text { technique to derive cloud top } \\
\text { height. This approach is } \\
\text { insensitive to calibration and does } \\
\text { not rely on any assumptions } \\
\text { regarding atmospheric temperature } \\
\text { lapse rate. The approach works } \\
\text { well except for exceptionally } \\
\text { diffuse high clouds, representing a } \\
\text { failure rate of only a few percent. } \\
50 \text { m resolution images can be used } \\
\text { to determine cloud-top-height with } \\
\text { precision of about } 50 \text { m assuming } \\
\text { view angles at }+/-45 \text { degrees from } \\
\text { nadir. }\end{array}$ \\
\hline 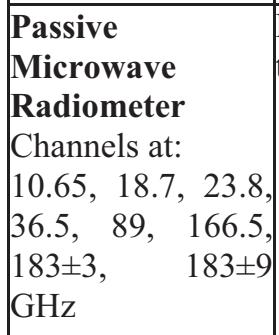 & \begin{tabular}{|l} 
Brightness \\
temperature
\end{tabular} & $\begin{array}{l}\text { Column liquid water path } \\
\left(3^{\text {rd }} \text { moment of drop size }\right. \\
\text { distribution) } \\
\text { Column water vapor path } \\
\text { Surface precipitation rate }\end{array}$ & $\begin{array}{l}\text { - } \text { Column constraint } \\
\text { - Will provide wide-swath / cloud } \\
\text { system context to narrow-swath } \\
\text { observations and in particular } \\
\text { information on precipitation. }\end{array}$ \\
\hline 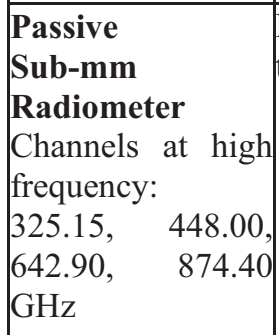 & $\begin{array}{l}\text { Brightness } \\
\text { temperature }\end{array}$ & $\begin{array}{l}\text { Column ice and size } \\
\text { constraint for ice clouds; } \\
\text { proportional to the } 3^{\text {r }} \\
\text { moment of particle size } \\
\text { distribution }\end{array}$ & $\begin{array}{l}\text { - } \text { Column constraint } \\
\text { - Will provide wide-swath / cloud } \\
\text { system context to narrow-swath } \\
\text { observations. }\end{array}$ \\
\hline \begin{tabular}{|l|} 
Wide-Swath \\
Infrared \\
Radiometer
\end{tabular} & Infrared radiances & 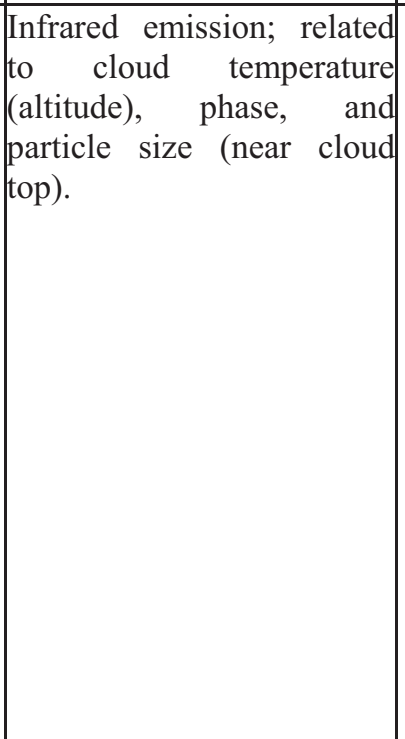 & $\begin{array}{l}\text { - } \begin{array}{l}\text { Support ocean color and extended- } \\
\text { region aerosol work. }\end{array} \\
\text { - Supply contextual information. } \\
\text { - Infer cloud-top-heights and optical } \\
\text { properties of the broad cloud } \\
\text { system. } \\
\text { - Support night time operations (IR } \\
\text { approach can be used to estimate } \\
\text { cloud top heights using during day } \\
\text { and night.) } \\
\text { - Large } 2.1 \text { um vs. } 3.7 \text { um retrievals } \\
\text { in boundary-layer clouds appear to } \\
\text { provide detection of drizzle/precip. } \\
\text { modes }\end{array}$ \\
\hline
\end{tabular}




\section{Concluding Remarks}

Addressing the anthropogenic impact to a changing global climate system requires levels of accuracy in prediction of temperature and precipitation that are presently well beyond the capability of current-day simulation tools. Simply increasing the computational resources available for climate modeling (i.e. increasing the resolution), while necessary, is by no means sufficient to improve the simulation accuracy to the level required for developing robust public policy in response to climate change. What is lacking is a fundamental ability to model the cycling of water and energy through the climate system. This cycling ultimately occurs at the particle level where aerosols grow to cloud droplets in saturated up- and downdrafts that may eventually become precipitation. An understanding of these processes is fundamental to proper climate change prediction yet this understanding does not now exist and therefore cannot be simulated.

We have considered what observational constraints on climate processes will be necessary to simulate the climate system at the end of the $2^{\text {nd }}$ decade of the $21^{\text {st }}$ century given the present trajectory in computer power. The observational system described in this document is the result of that process. The essence of this problem, even when considering a small atmospheric volume that contains condensed water, is complicated and requires multiple measurements that provide independent constraints on the characteristics of the hydrometeor and aerosol size distributions and vertical motion within a volume. This requirement for multiple independent constraints within cloudy volumes will drive the cost and complexity of the ACE mission, yet such complexity is necessary to meet the fundamental goals of the ACE mission. Our objectives in the near term are to critically evaluate the tradeoffs between complexity that ultimately drives cost and the requirements to accomplish the science goals of ACE. 


\section{References}

[1] IPCC, [Climate Change 2007: The Physical Science Basis. Contribution of Working Group I to the Fourth Assessment Report of the Intergovernmental Panel on Climate Change], Solomon, S., D. Qin, M. Manning, Z. Chen, M. Marquis, K.B. Averyt, M.Tignor and H.L. Miller (eds.), Cambridge University Press, Cambridge, United Kingdom and New York, NY, USA, (2007).

[2] Kiehl, J. T., "Twentieth century climate model response and climate sensitivity", Geophys. Res. Lett., 34, L22710, doi:10.1029/2007GL031383, (2007).

[3] Forster, P., V. Ramaswamy, P. Artaxo, T. Berntsen, R. Betts, D.W. Fahey, J. Haywood, J. Lean, D.C. Lowe, G. Myhre, J. Nganga, R. Prinn, G. Raga, M. Schulz and R. Van Dorland, Changes in Atmospheric Constituents and in Radiative Forcing. In: Climate Change 2007: The Physical Science Basis. Contribution of Working Group I to the Fourth Assessment Report of the Intergovernmental Panel on Climate Change [Solomon, S., D. Qin, M. Manning, Z. Chen, M. Marquis, K.B. Averyt, M.Tignor and H.L. Miller (eds.)]. Cambridge University Press, Cambridge, United Kingdom and New York, NY, USA, (2007).

[4] Morrison, H., J. A. Curry, and V. I. Khvorostyanov, "A new double-moment microphysics parameterization for application in cloud and climate models. Part I: Description”, J. Atmos. Sci., 62, 1665-1677, (2005).

[5] Morrison, H., and A. Gettelman, "A new two-moment bulk stratiform cloud microphysics scheme in the community atmosphere model, version 3 (CAM3). Part I: Description and Numerical Tests", J. Climate, 21, 3642-3659, DOI: 10.1175/2008JCLI2105.1, (2008).

[6] Stephens, G. L., "Cloud feedbacks in the climate system: A critical review", J. Atmos. Sci., 18, 237-235, (2005).

[7] Mace G. G., "Cloud properties and radiative forcing over the maritime storm tracks of the Southern Ocean and North Atlantic derived from A-Train”, Journal of Geophys. Res., 115, doi:10.1029/2009JD012517, (2010).

[8] Fu, Q., P. Yang, and W. B. Sun, "An accurate parameterization of the infrared radiative properties of cirrus clouds for climate models", J. Climate, 9, 2223-2237, (1998).

[9] Vogelmann, A. M., and T. P. Ackerman, "Relating cirrus cloud properties to observed fluxes: A critical assessment", J. Atmos. Sci., 52, 4285-4301, (1995).

[10] Comstock, J. M, T. P. Ackerman and G. G. Mace, "Ground-based lidar and radar remote sensing of tropical cirus clouds at Nauru Island: Cloud statistics and radiative impacts", J. Geophys. Res., 107, 1771-1790, (2002).

[11] Gultepe, I, and D. O'C Starr, "Dynamical structure and turbulence in cirrus clouds: Aircraft observations from FIRE", J. Atmos. Sci, 52, 4159-4182, (1995).

[12] Bony, S., R. Colman, V. M., Kattsov, R. P. Allan, C. S. Bretherton, J-L. Dufresne, A. Hall, S. Hallegatte,M. M. Holland, W. Ingram, D. A. Randall, B. J. Soden, G. Tselioudis, and M. J. Webb, "How well do we understand and evaluate climate change feedback processes?", J. Climate, 19, 3445-2461, (2006).

[13] Marchand, R., T. Ackerman, E. R. Westwater, S. A. Clough, K. Cady-Pereira, and J. C. Liljegren, "An assessment of microwave absorption model and retrievals of cloud liquid water using clear-sky data", $J$. Geophys. Res., 108 (24), DOI 1.1029/2003JD003843, (2003).

[14] Wood, R. and D. L. Hartmann, "Spatial variability of liquid water path in marine low cloud: The importance of mesoscale cellular convection", J. Climate, 19, 1748-1765, (2006).

[15] Fridlind, A. M., and A. S. Ackerman, "Estimating the sensitivity of radiative impacts of shallow, broken marine clouds to boundary layer aerosol size distribution parameter uncertainties for evaluation of satellite retrieval requirements", J. Atmos. Oceanic Technol., 28, 530-538, (2011).

[16] Twomey, S., Aerosols, "Clouds and radiation", Atmos. Environ., 25A, 2435-2442, (1991). 